\title{
燃料电池
}

庄林

武汉大学化学与分子科学学院, 武汉 430072

\section{Fuel Cells}

\section{Lin Zhuang}

College of Chemistry and Molecular Sciences, Wuhan University, Wuhan 430072, China.

Email: lzhuang@whu.edu.cn

Published online: January 5, 2021.

燃料电池是一种发电装置, 它突破了卡诺循 环的限制, 有望获得更高的能量利用效率。目前, 使用质子交换膜(PEM)作为电解质的质子交换膜 燃料电池(PEMFCs) 是最有可能商用化的车用燃 料电池。日本丰田Mirai车型使用的燃料电池技术 代表了目前最先进的PEMFCs技术。随着PEMFCs 阴、阳极贵金属催化剂用量的不断减少(Mirai的Pt 载量为 $0.15 \mathrm{mg} \cdot \mathrm{cm}^{-2}$ ), 催化剂的成本占比也逐渐下 降。目前的高压储氢罐压力最高可以达到 $80 \mathrm{MPa}$, 可以满足商品化的需求。此外, 包括流场、双极板、 空压机、氢气循环洜在内的附件和辅助系统也有 了全球大量企业的研发投入, 使研究者看到了 PEMFCs商品化的曙光。在此基础上, 进一步降低 催化剂的用量, 提高催化剂的稳定性, 对增加 PEMFCs商品化竞争力仍然是有价值的。

尽管PEMFCs目前的成本相比早年已显著下 降, 但想在激烈的商业竞争中超越传统内燃机汽 车, 以及使用锂离子电池为代表的电动汽车, 成本 问题依旧不容忽视。使用碱性聚电解质(APE)的碱 性聚电解质燃料电池(APEFCs) 能够使用价格低廉 的非贵金属催化剂, 并且催化剂的来源不受战略 资源的限制(我国的Pt矿藏有限), 作为PEMFCs的 备用技术依然受到各国的重视。随着APE的性能、 稳定性和机械强度的不断提高, APEFCs的电池性 能也不断被刷新。近年来APEFCs的功率密度已经 突破 $3 \mathrm{~W} \cdot \mathrm{cm}^{-2}$, 与PEMFCs的差距在不断缩小。在 此基础上, 阴、阳极非贵金属催化剂的性能及稳定 性研究, APE的稳定性研究正成为APEFCs研究的 重点。
本特刊专辑邀请了国内部分从事然料电池研 究的学者团队, 介绍他们近年来在燃料电池方面 的研究进展和总结。下面对这些研究和总结进行 扼要介绍。

李剑锋等 1 综述了拉曼光谱以及表面增强拉曼 光谱技术(SERS)和壳层隔绝表面增强拉曼光谱技 术(SHINERS)在燃料电池中的应用, 从拉曼光谱在 电池材料表征方面到界面电催化反应过程中中间 物种分子的结构及吸附构型等方面的研究进行综 合评述，并探讨其未来的发展方向。

李莉、魏子栋等 2 综述了近年来碱性介质中氢 氧化反应(HOR)和析氢反应(HER)机理的相关解 释与推论, 主要包括双功能机理、氢结合能(HBE) 理论和电子效应, 以及对各观点存在的争议进行 总结和讨论; 并从理论计算的角度, 介绍目前电化 学界面的理论模拟方法的发展及其在 HOR/HER 研究中的应用。

张进涛等 3 综述了近年来杂原子掺杂以及过渡 金属与杂原子协同掺杂碳基催化剂的设计思路及 其氧还原催化活性的影响规律和燃料电池中的性 能优化等最新研究进展, 并对未来发展方向进行 了总结与展望。

宋玉江等 ${ }^{4}$ 以非金属氮掺碳电催化剂为载体, 通过引入活性物质 $\mathrm{FeP}$ 和模板 $\mathrm{SiO}_{2}$ 制备了具有丰 富孔结构、较大比表面积的 $\mathrm{FeP}$ 修饰多孔聚苯胺 (PANI)基非贵金属氧还原(ORR)电催化剂, 在碱性 介质中表现出较高的 $\mathrm{ORR}$ 活性和优于商业 $\mathrm{Pt} / \mathrm{C}$ 的 耐久性。

杨泽惠等 5 综述了铂基催化剂、非铂催化剂和 
非金属催化剂在中高温质子交换膜燃料电池中的 应用现状, 重点阐述了表面修饰、合金化、载体效 应等策略对催化剂在磷酸电解液中的氧还原反应 动力学的影响。

丁炜、魏子栋等6综述超低铂负载下燃料电池 阴极性能的最新进展, 主要集中在开发高活性、高 利用率、高稳定的、抗溺水的新型铂基催化剂; 开 发高透氧率、疏水性新型离聚物, 制备超薄质子 膜; 合理设计高传质性能、高利用率的催化层。

张存满等 ${ }^{7}$ 总结了导电填料及树脂的性质、改 性方法等对于复合石墨极板性能的影响, 并分析 了分子结构以及制备工艺对于极板结构以及实用 性能的影响规律。

李等等 8 综述了近年来提升质子交换膜燃料电 池氧还原反应铂基催化剂稳定性的原理、策略与 方法, 从热力学和动力学上阐述影响催化剂稳定 性的原因及其调控原理, 此外还总结了一些具有 代表性的提升催化剂稳定性的策略和方法。

王得丽等 ${ }^{9}$ 基于多年来在有序金属间化合物电 催化剂方面的研究，综述了贵金属基有序金属间 化合物电催化剂的研究现状。重点介绍了 $\mathrm{Pt} / \mathrm{Pd}$ 基 金属间化合物的结构特点、表征方法、可控制备以 及其在燃料电池电催化剂中的应用。

卢善富等 ${ }^{10}$ 对近年来高温膜电极(HT-MEA)中 磷酸的分布、动态迁移过程的研究现状进行了梳 理分析, 对HT-MEA (包括高温聚合物电解质膜和 催化层) 中磷酸分布和迁移的调节与优化策略研 究进展进行了较全面的综述, 尤其是针对磷酸降 低电解质膜力学强度、酸淹催化层、毒化催化剂和 磷酸流失等关键科学问题。

冯立刚等 ${ }^{11}$ 采用简便的冷冻干燥/退火还原的 方法将PdNi以合金纳米粒子形式分散在三维石墨 烯气凝胶 $(\mathrm{PdNi} / \mathrm{GA})$ 表面, 在二元协同和电子效应 的驱动下实现了对甲酸氧化反应的高效催化。

夏宝玉等 ${ }^{12}$ 简要综述了铂基纳米框架电催化 剂的最新进展, 介绍了不同的铂基纳米框架的制 备、蚀刻策略和结构演变过程, 还重点讨论了铂基 纳米框架在直接醇燃料电池中氧还原反应和醇氧 化反应的电催化性能, 主要包括铂基纳米框架的 催化活性、抗中毒能力和耐久性。

苏华能等 ${ }^{13}$ 制备了一种席夫碱型(SNW-1)共价 有机框架 (COF) 材料并将其加入到的电极催化层 中, 由于 $\mathrm{COF}$ 的良好的磷酸保留能力和质子转移 能力减少了膜电极(MEA)中的磷酸流失, 该催化 层掺杂共价有机框架材料的高温聚电解质膜燃料 电池在电池加速老化测试中展现出很好稳定性。
庄仲滨等 ${ }^{14}$ 综述了碱性膜燃料电池阳极催化 剂的研究进展, 总结了文献中提出的各种HOR机 理和催化剂, 尤其是非Pt HOR催化剂, 可以到达 与质子膜燃料电池接近的成本水平。

胡劲松等 15 综述了基于金属-氮-碳催化剂的质 子交换膜燃料电池性能与活性位点、催化剂结构 和催化层结构之间的关系, 揭示了催化剂结构对 于质子交换膜燃料电池中物质传输的重要作用。 此外, 还总结并讨论了质子交换膜燃料电池可能 的失活机理, 包括脱金属作用, 氮物种的质子化, 碳载体腐蚀和孔道水淹等, 以及目前发展的可能 的解决方案。

\section{References}

(1) Zhang, Y. J.; Zhu, Y. Z.; Li, J. F. Acta Phys. -Chim. Sin. 2021, 37, 2004052. [张月皎, 朱越洲, 李剑锋. 物理化学学报, 2021, 37, 2004052.] doi: 10.3866/PKU.WHXB202004052

(2) Li, M. T.; Zheng, X. Q.; Li, L.; Wei, Z. D. Acta Phys. -Chim. Sin. 2021, 37, 2007054. [李孟婷, 郑星群, 李莉, 魏子栋. 物理化学学 报, 2021, 37, 2007054.] doi: 10.3866/PKU.WHXB202007054

(3) Liu, M. M.; Yang, M. M.; Shu, X. X.; Zhang, J. T. Acta Phys. -Chim. Sin. 2021, 37, 2007072. [刘苗苗, 杨茅茂, 舒欣欣, 张进涛. 物理 化学学报, 2021, 37, 2007072.] doi: 10.3866/PKU.WHXB202007072

(4) Han, H. S.; Wang, Y. Q.; Zhang, Y. L.; Cong, Y. Y.; Qin, J. Q.; Gao, R.; Cai, C. X.; Song, Y. J. Acta Phys. -Chim. Sin. 2021, 37, 2008017. [韩洪仨, 王彦青, 张云龙, 丛媛媛, 秦嘉琪, 高芯, 柴春晓, 宋玉 江. 物理化学学报, 2021, 37, 2008017.] doi: 10.3866/PKU.WHXB202008017

(5) Luo, F.; Pan, S. Y.; Yang, Z. H. Acta Phys. -Chim. Sin. 2021, 37, 2009087. [罗芳, 潘书媛, 杨泽惠. 物理化学学报, 2021, 37, 2009087.] doi: 10.3866/PKU.WHXB202009087

(6) Wang, J.; Ding, W.; Wei, Z. D. Acta Phys. -Chim. Sin. 2021, 37, 2009094. [王健, 丁炜, 魏子栋. 物理化学学报, 2021, 37, 2009094.] doi: 10.3866/PKU.WHXB202009094

(7) Fan, R. L.; Peng, Y. H.; Tian, H.; Zheng, J. S.; Ming, P. W.; Zhang, C. M. Acta Phys. -Chim. Sin. 2021, 37, 2009095. [樊润林, 彭宇航, 田 豪, 郑俊生, 明平文, 张存满. 物理化学学报, 2021, 37, 2009095.] doi: 10.3866/PKU.WHXB202009095

(8) Liang, J. S.; Liu, X.; Li, Q. Acta Phys. -Chim. Sin. 2021, 37, 2010072. [梁嘉顺, 刘轩, 李等. 物理化学学报, 2021, 37, 2010072.] doi: 10.3866/PKU.WHXB202010072

(9) Li, Z. R.; Shen, T.; Hu, Y. Z.; Chen, K.; Lu, Y.; Wang, D. L. Acta Phys. -Chim. Sin. 2021, 37, 2010029. [李峥湈, 申涛, 胡冶州, 陈科, 陆䐝, 王得丽. 物理化学学报, 2021, 37, 2010029.] doi: 10.3866/PKU.WHXB202010029

(10) Zhang, J. J.; Zhang, J.; Wang, H. N.; Xiang, Y.; Lu, S. F. Acta 
Phys. -Chim. Sin. 2021, 37, 2010071. [张巨佳, 张劲, 王海宁, 相艳, 卢善富. 物理化学学报, 2021, 37, 2010071.]

doi: 10.3866/PKU.WHXB202010071

(11) Bao, Y. F.; Feng, L. G. Acta Phys. -Chim. Sin. 2021, 37, 2008031. [包 玉菲, 冯立纲. 物理化学学报, 2021, 37, 2008031.] doi: 10.3866/PKU.WHXB202008031

(12) Huang, L.; Zaman, S.; Wang, Z. T.; Niu, H. T.; You, B.; Xia, B. Y. Acta Phys. -Chim. Sin. 2021, 37, 2009035. [黄否, Shahid Zaman, 王 志同, 牛慧婷, 游波, 夏宝玉. 物理化学学报, 2021, 37, 2009035.] doi: 10.3866/PKU.WHXB202009035

(13) Tian, L. L.; Zhang, W. Q.; Xie, Z.; Peng, K.; Ma, Q.; Xu, Q.; Pasupathi, S.; Su, H. N. Acta Phys. -Chim. Sin. 2021, 37, 2009049.
[田立亮, 张玮琦, 解政, 彭凯, 马强, 徐谦, Sivakumar Pasupathi, 苏华能. 物理化学学报, 2021, 37, 2009049.] doi:

10.3866/PKU.WHXB202009049

(14) Xue, Y. R.; Wang, X. D.; Zhang, X. Q.; Fang, J. J.; Xu, Z. Y.; Zhang, Y. F.; Liu, X. R.; Liu, M. Y.; Zhu, W.; Zhuang, Z. B. Acta Phys. -Chim. Sin. 2021, 37, 2009103. [薛延荣, 王兴栋, 张向前, 方锦杰, 许志 远, 张宇烽, 刘雪瑞, 刘梦园, 朱威, 庄仲滨. 物理化学学报, 2021, 37, 2009103.] doi: 10.3866/PKU.WHXB202009103

(15) Ding, L.; Tang, T.; Hu, J. S. Acta Phys. -Chim. Sin. 2021, 37, 2010048. [丁亮, 唐堂, 胡劲松. 物理化学学报, 2021, 37, 2010048.] doi: 10.3866/PKU.WHXB202010048 